\title{
Gagasan Syekh Sulaiman Al-Rasuli tentang Pendidikan Islam dan Penerapannya pada Madrasah Tarbiyah Islamiyah di Sumatera Barat
}

\author{
Muhammad Kosim ${ }^{1}$
}

\section{A. PENDAHULUAN}

\section{Latar Belakang Masalah}

Syekh Sulaiman al-Rasuli, juga dikenal dengan sebutan Inyiak Canduang, merupakan ulama Minangkabau terkemuka di kalangan kaum tua yang berperan aktif dalam mempertahankan I'tiqad Ahl al-Sunnah wa al-Jamā'ah dan berpegang pada Mazhab Syafi'i; suatu pemahaman yang banyak hal bertentangan dengan ulama kaum muda. Ketika kaum muda melakukan perubahan sistem pendidikan dari halaqah menjadi klasikal, sementara ulama kaum tua lainnya masih mempertahankan sistem pendidikan halaqah di surau, Syekh Sulaiman justru merestui perubahan tersebut, atas dorongan ulama senior yang juga sahabatnya, Syekh Abbas Qadhi Ladang Lawas tahun 1926 (Bahruddin Rusli, 1978: 33).

Dua tahun kemudian, 1928, langkah Syekh Sulaiman al-Rasuli diikuti oleh ulama sepaham dengannya, seperti Syekh Abdul Wahid al-Shalihi Tabek Gadang di Payakumbuh, Syekh Muhammad Jamil Jaho di Padang Panjang, Syekh Arifin di Batu Hampar Payakumbuh, dan lain-lain (Chairusdi, 1999: 50-51). Dalam pertemuan di tahun tersebut, lahirlah "Persatuan Madrasah Tarbiyah Islamiyah" (PMTI) sebagai organisasi yang bertanggung jawab untuk membina, memperjuangkan, dan mengembangkan MTI-MTI yang ada. Perkembangan selanjutnya, PMTI tidak hanya sebagai organisasi yang mengurus madrasah an sich, akan tetapi mampu mempersatukan dan menghimpun segenap ulama tradisional dan bergerak di bidang sosial lainnya. PMTI pun berubah menjadi PTI (Persatuan Tarbiyah Islamiyah) di tahun 1930 dan singkatannya diubah lagi menjadi PERTI sekitar tahun 1937 (Majalah Soearti No. 8 Th. I/Januari 1938 $\mathrm{M})$.

Dengan begitu, Syekh Sulaiman al-Rasuli adalah praktisi pendidikan yang berpengaruh di zamannya, khususnya di kalangan

${ }^{1}$ Penulis adalah Alumnus Program Doktor IAIN Imam Bonjol Padang 


\section{At-Tarbiyah}

kaum Tua. Tidak saja sebagai praktisi pendidikan, tetapi ia memiliki beberapa gagasan tentang pendidikan Islam yang ia tulis di beberapa karyanya. Melakukan kajian terhadap gagasan pendidikan Islam Syekh Sulaiman al-Rasuli semakin penting dilakukan mengingat ketokohannya selama ini lebih cenderung dinilai sebagai ahli di bidang fiqh (Bahruddin Rusli, 1972: 3). Apalagi dalam perjalanan hidupnya ia pernah diangkat sebagai Qadhi yang berwenang mengurusi masalah nikah, talak, dan ruju' (NTR) sejak tahun 1917. Bahkan pada tahun 1947-1960 ia menjabat sebagai kepala pertama pada Mahkamah Syar'iyyah Provinsi Sumatera Tengah (Edwar [ed.], 1981: 82-85).

Menarik pula untuk diteliti, sebagai tokoh utama pendiri MTI, apakah pemikiran Inyiak Canduang masih diterapkan oleh MTI yang masih eksis hingga hari ini atau tidak. Idealnya, ide-ide bernasnya tentang pendidikan Islam itu tetap diterapkan di MTI sebagai warisan pemikiran dan menjadi tradisi yang terpelihara secara turun-temurun. Karena itu, penelitian ini berjudul "Gagasan Syekh Sulaiman al-Rasuli tentang Pendidikan Islam dan Penerapannya pada Madrasah Tarbiyah Islamiyah di Sumatera Barat."

\section{Rumusan dan Batasan Masalah}

Rumusan masalah: "Bagaimanakah gagasan Syekh Sulaiman al-Rasuli tentang pendidikan Islam dan penerapannya pada Madrasah Tarbiyah Islamiyah yang ada di Provinsi Sumatera Barat? Batasan masalah: (1) Bagaimanakah gagasan Syekh Sulaiman al-Rasuli tentang pendidikan Islam yang meliputi: hakikat manusia, tujuan pendidikan, materi, metode, pendidik,peserta didik dan pendidikan informal; serta (2) Bagaimanakah penerapan gagasan Syekh Sulaiman al-Rasuli terhadap pelaksanaan pendidikan Islam di Madrasah Tarbiyah Islamiyah (MTI) yang ada di Provinsi Sumatera Barat saat ini yang meliputi MTI Canduang, MTI Jaho, dan MTI Batang Kabung?

\section{METODOLOGI PENELITIAN}

Jenis penelitian dalam disertasi ini ada tiga, yaitu: pertama, penelitian tokoh, dilakukan untuk menemukan biografi Syekh

Sulaiman al-Rasuli; kedua, penelitian kepustakaan (library 234 | Gagasan Syekh Sulaiman Al-Rasuli... 
research), mengkaji gagasan Syekh Sulaiman al-Rasuli dari karyakaryanya tentang pendidikan Islam; ketiga, penelitian lapangan (field research), mengkaji penerapan gagasan Syekh Sulaiman al-Rasuli pada Madrasah Tarbiyah Islamiyah (MTI) dengan tiga lokasi, yaitu MTI Canduang Kab. Agam, MTI Jaho Kab. Tanah Datar, dan MTI Batang Kabung Kota Padang.

Ketiga jenis penelitian ini menggunakan metode kualitatif dengan pendekatan: 1) hermeneutik; 2) teologis; 3) pedagogis; 4) sejarah (historical approach); 5) fenomenologi; dan 6) etnometodologi.

Sumber data primer adalah karya tulis dari Syekh Sulaiman al-Rasuli yang tidak kurang dari 15 buku, di antaranya yang paling menonjol adalah: 1) Pedoman Hidoep di Alam Minangkabau (Nasihat Siti Boediman) Menoeroet Garisan Adat dan Sjara'. 2) Jawāhir al-Kalāmiyah fi al-i'tiqād ahl al-Sunnah. 3) Risālah al-Qaul al-Bayān fì Tafsīr al-Qur'ān. 4) Enam Risalah, 5) Tablīgh al-Amānā. Sedangkan sumber data sekunder adalah hasil penelitian dan bukubuku yang mengkaji tentang Syekh Sulaiman al-Rasuli, Madrasah Tarbiyah Islamiyah, dan Persatuan Tarbiyah Islamiyah.

Informan dalam penelitian ini adalah unsur pimpinan, guru, santri, dan alumni dari tiga MTI tersebut. Lalu orang-orang yang pernah bertemu dengan Syekh Sulaiman, termasuk keluarga, murid, tokoh masyarakat dan orang-orang yang berseberangan pemikiran dengannya. Teknik sampel yang digunakan: purposive sampling dan snowball sampling. Dalam penelitian ketokohannya, dilakukan melalui tahap orientasi, tahap eksplorasi, dan tahap studi terfokus. Sedangkan pengumpulan data lapangan dilakukan dengan metode dokumentasi, wawancara dan obeservasi.

\section{HASIL PENELITIAN}

\section{Biografi Ringkas Syekh Sulaiman al-Rasuli}

Nama lengkapnya adalah Muhammad Sulaiman bin Muhammad Rasul. Ia lahir pada petang Ahad malam Senin tanggal 10 Desember 1871 M bertepatan bulan Muharram 1297 H di Surau Pakan Kamis, Nagari Canduang Koto Laweh, Kabupaten Agam, Provinsi Sumatera Barat. Di antara gurunya adalah: Syekh Muhammad Arsyad (1899-1924 M), anak dari Syekh Abdurrahman al-Khalidi (kakek 


\section{At-Tarbiyah}

proklamator Moh. Hatta), di Batu Hampar, Payakumbuh; Syekh Abdussamad Tuanku Samiak Ilmiyah, di suraunya di Biaro IV Angkat Agam, tahun 1309 H; Syekh Mohammad Ali Tuanku Kolok-kakek pihak ibu dari Prof. Mahmud Yunus - di Tanjung Sungayang Kab. Tanah Datar; Syekh Abdussalam, di Lokok Banuhampu; Syekh Muhammad Salim al-Khalidi di Sungai Dareh Situjuh Payakumbuh; dan Syekh Abdullah di Halaban.

Tahun $1322 \mathrm{H}$, ia naik haji dan belajar selama 3,5 tahun (1903-1907 M). Di antara gurunya: 1) Syekh Ahmad Khatib al-Minangkabawy, 2) Syekh Mukhtar 'Atharad as-Shufy, 3) Syekh Usman al-Sirwaqy, 4) Syekh Muhammad Sa'id Mufty al-Syafe'i, 5) Syekh Nawawi Banten, 6) Syekh Ali Kutan al-Kelantani, 7) Syekh Ahmad Muhammad Zain al-Fathani, 8) Said Ahmad Syatha al-Maky, 9) Said Umar Bajaned, dan 10) Said Babasil Yaman (Yusran Ilyas, 195: 5).

Sekembalinya ke tanah air, ia berkiprah di bidang pendidikan, tabligh dan politik. Dialah tokoh utama dalam pendirian Madrasah Tarbiyah Islamiyah (MTI) Canduang yang kemudian menjadi sentral bagi MTI lain. Ia tidak saja berdakwah di sekitar Canduang dan Baso, tetapi juga membina masyarakat di Pandai Sikat Padang Panjang yang nyaris terjerumus kepada kemusyrikan. Pada tahun $1341 \mathrm{H}$, ia pergi berkhalwat ke Batu Hampar melalui tarekat Naqsyabandiyah dan setelah itu ia tampil mempertahankan ajaran tarekat tersebut (Muhammad Rusli Kapau, 1938: 56).

Pada masa Belanda, sejumlah jabatan yang diembannya adalah: sebagai Qadhi di nagari Canduang dalam Sidang Sabuah Balai tahun 1917-1944; Ketua Umum Syarikat Islam (SI) untuk daerah Canduang - Baso tahun 1918 M. Bersama Syekh H. Abbas al-Qadhi Ladang Lawas dan Syekh H. Muhammad Jamil Jaho serta ulama yang sepaham, ia mendirikan organisasi "Vereeniging Ittihadul Oelama Sumatera” (VIOS) tahun 1921 M; pendiri utama dan direktur bidang Pendidikan Persatuan Madrasah Tarbiyah Islamiyah (PMTI) yang terbentuk pada tanggal 5 Mei 1928 M/15 Zulkaedah 1346 H. Tahun $1932 \mathrm{M}$ ia menolak ordonansi sekolah liar yang diberlakukan oleh pemerintah kolonial Belanda. Tahun 1937, ia turut menolak ordonansi kawin bercatat. Ia pernah dikunjungi oleh utusan Belanda, begitu juga tokoh nasional, Ir. Soekarno sebelum menjadi presiden RI. Tahun 1939, bersama ulama lain ia membentuk kepanduan al-Anshar, tahun 1942 ia turut menentang Politik Bumi Hangus Kolonial (Yusran Ilyas, 
Volume V No. 2, Agustus 2014

1955: 8). Pada masa penjajahan Jepang, Ia menjadi Ketua Umum Majelis Islam Tinggi Minangkabau (MITM). Ia turut mewakili MITM menghadiri Rapat Besar Ulama Islam Sumatera-Malaya di Singapura (Syonanto).

Masa Pascakemerdekaan, PERTI menjadi partai politik Islam, tanggal 22 Nopember 1945, ia ditetapkan sebagai Penasehat Tertinggi. Tahun 1947 berdirilah Mahkamah Syar'iyah di Sumatera Tengah dan ia diangkat menjadi Ketua oleh Menteri Agama RI, tanggal 17 Juni 1947 dan berakhir tahun 1960 M. Tahun 1948, ia diangkat sebagai penasehat Gubernur Militer Sumatera Tengah. Tahun 1956, ia menghadiri Muktamar Ulama Seluruh Indonesia (MUSI) di Palembang dan ia dipercaya sebagai ketua salah satu komisi yang membahas upaya untuk menentang komunis. Ia juga menjadi anggota Konstituante berdasarkan hasil PEMILU pertama tahun 1955, pada sidang pertama dibuka 10 Nopember 1956 di Kota Bandung dan ia terpilih menjadi ketua sidang pertama konstituante tersebut. Dalam memimpin sidang, ia mengenakan sarung dan sorban, pakaian yang biasa dipakainya (Hasril Chaniago, 2010: 475).

Ia juga ahli di bidang adat Minangkabau dan menulis beberapa buku tentang adat Minangkabau. Tahun 1927, ia diundang untuk menjadi nara sumber tentang keterkaitan Islam dengan adat Minangkabau di daerah raja-raja Gunung Sahilan (Zelf Besturder van Kampar Kiri), Teluk Kuantan dan Pulau Gadang. Tahun 1954 dilaksanakan "Kongres Segi Tiga" berdasarkan inisiatifnya dan ia ditetapkan sebagai ketua umum (Bahruddin Rusli, 1978: 69). Bahkan Gusti Asnan (2003: 308) menyebutkan: "Pada tahun 1950-an, Syekh Sulaiman al-Rasuli sangat bersemangat menyebarluaskan gagasan tentang keterpaduan adat dan Syarak. Ungkapan Adat Basandi Syarak, Syarak Basandi Kitabullah yang dewasa ini populer merupakan hasil "sosialisasi" dari ulama besar ini dalam berbagai kesempatan sepanjang dasawarsa 1950-an."

Tepat pada hari Sabtu, tanggal 28 Rabi'ul Akhir 1390 H/1 Agustus 1970, Syekh Sulaiman al-Rasuli wafat dalam usia 99 tahun. Tidak kurang dari enam ribu pelayat yang mengantarkan jenazahnya ke pemakaman di halaman madrasah induk yang asli dari MTI Canduang, termasuk yang hadir Gubernur Sumatera Barat, Harun Zein. Bahkan Gubernur, memerintahkan agar pemerintah dan rakyat mengibarkan bendera setengah tiang, sebagai tanda belasungkawa. Di hari itu, sedang berlangsung seminar sejarah Islam di Minangkabau yang 


\section{At-Tarbiyah}

dihadiri oleh sejumlah cendikiawan, termasuk Buya Hamka. Buya Hamka langsung menuju Canduang dan shalat jenazah di atas pusara. Dalam pidatonya Hamka menyebut bahwa Syekh Sulaiman al-Rasuli seperti pohon pisang, sekali dipancung, ia tidak akan mati tetapi akan tumbuh pohon pisang yang baru ditambah dengan pisang-pisang yang lain di sekelilingnya. Ungkapan ini menggambarkan bahwa perjuangan dan ajaran Syekh Sulaiman al-Rasuli tidak akan pernah mati, tetapi akan dilanjutkan oleh ribuan murid-muridnya (Maruzi Kari Batuah, Wawancara, 8 Juli 2013).

2. Sekilas tentang MTI Canduang, MTI Jaho dan MTI Batang Kabung

MTI Canduang beralamat di Jl. Syekh Sulaiman al-Rasuli, Jorong Lubuk Aur Kenagarian Canduang Koto Laweh, Kecamatan Canduang, Kabupaten Agam. Berdiri tanggal 15 Zulkaedah 1346 H/5 Mei 1928 M yang langsung dipimpin oleh Syekh Sulaiman al-Rasuli. Di tahun 2013, MTI ini dipimpin oleh Buya Amhar Zen al-Rasuli. Terdapat tujuh tingkatan kelas dengan jumlah 811 santri.

MTI Jaho berada di Nagari Jaho Kecamatan X Koto Kabupaten Tanah Datar. Berdiri tahun 1928 oleh Syekh Muhammad Jamil Jaho, yang merupakan sahabat dekat Syekh Sulaiman al-Rasuli dan selama 7,5 tahun belajar di Mekah. Di tahun 2013, MTI Jaho dipimpin oleh Buya Asmuji Rais al-Jamily. Terdapat enam tingkatan kelas, namun secara kuantitas jumlah santi megalami penurunan drastis, yaitu hanya 80 santri.

MTI Batang Kabung terletak di Kelurahan Batang Kabung Ganting, Kec. Koto Tangah, Kota Padang. Berdiri sejak tanggal 13 Januari 1955 M dalam bentuk halaqah yang dipimpin oleh Syekh Angku Salif. Tahun 1966 berubah menjadi madrasah (klasikal) dan pimpinannya mendapat ijazah dari Syekh Sulaiman al-Rasuli sebagai salah satu syarat mendirikan madrasah ketika itu. Di tahun 2013, MTI ini dipimpin oleh Jamaris Tuangku Mudo sebagai khalifah I, H. Idris Tuanku Mudo sebagai khalifah II, dan Mahyuddin Salif Tuanku Sutan sebagai khalifah III. Dari tingkat Tsanawiyah dan Aliyah, terdapat 663 santri. Di samping itu terdapat santri kelas VII dan VIII ( $m a$ 'had aly) sekitar 25 santri.

3. Gagasan Syekh Sulaiman al-Rasuli tentang Pendidikan Islam 


\section{1) Hakikat Manusia}

Hakikat manusia, dalam pandangan Syekh Sulaiman, dapat dirumuskan pada empat bagian. Pertama, manusia sebagai makhluk jasmani dan rohani. Ketika mengkaji manusia, ia menyebut manusia terdiri dari unsur jasmani dan rohani, tetapi dimensi rohani lebih mempengaruhi kepribadian seseorang. Menurutnya, asal mula sekalian makhluk adalah Nur Muhammad. Nur itu berpindah-pindah dari nabi hingga kepada orang-orang yang beriman; orang-orang yang memiliki kesucian rohani (Syekh Suliaman al-Rasuli, selanjutnya disebut SSA, 1923: 5). Ia juga menegaskan, ada dua penyakit manusia, yaitu bodoh (jāhil) dan lalai ( $g h \bar{a} f i l)$. Obat bodoh adalah ilmu, obat lalai adalah zikir (SSA, 1929: 129-130).

Kedua, manusia sebagai hamba ('abd) Allah dan khalīfahNya di muka bumi. Ia menulis, "Bermula makna beribadah ialah berhina diri sampai kepada kesudah-sudahan hina serta membesarkan akan orang yang disembah yang sampai kepada kesudah-sudahan membesarkan." (SSA, 1929: 6). Baginya, khaliffah yang paling ideal hanya ada pada diri Nabi Muhammad SAW, karena terdapat kemampuan untuk memimpin/mengatur dan kemampuan mendidik umatnya untuk senantiasa mampu menjalankan ibadah kepada Allah SWT. Jika tidak ditemukan lagi seorang pemimpin yang memiliki sifat-sifat sebagaimana layaknya khaliffah yang ideal tersebut, maka penguasa harus bertanya dan bekerjasama dengan ulama (SSA, 1927: 2)

Ketiga, manusia sebagai makhluk individu dan sosial. Ia mengklasifikasikan tipe manusia dalam lingkungan masyarakatnya, seperti yang ia tulis dalam kitabnya "Pedoman Hidoep di Alam Minangkabau" khususnya pada satu sub bahasan dengan judul "pembagian manusia." Secara garis besar, manusia itu dikelompokkannya kepada lima kategori, yaitu penghulu (pemimpin), ulama, urang mudo (pemuda), padusi (perempuan), dan urang tuo (orang tua). Setiap komponen masyarakat itu ada yang ideal, ada pula yang tidak. Pemuda, misalnya, yang ideal disebutnya pemuda pesurau, yaitu pemuda shaleh yang memakmurkan surau. Tetapi ada pemuda yang buruk, yaitu pemuda palapau (suka duduk di kedai dan kurang tanggung jawab pada keluarga), pemuda parinsau (suka mengeluh dan 


\section{At-Tarbiyah}

menyia-nyiakan waktu), pemuda pengusu (suka membuat onar), dan pemuda lingkisau (berpenyakit hati) (SSA, 1930: 59-65). Pengelompokan manusia seperti ini membuktikan bahwa ia juga memahami karakter manusia yang berbeda antara satu dengan lainnya. Setiap manusia harus berupaya untuk memposisikan dirinya sesuai dengan peran dan kapasitasnya masing-masing.

\section{2) Tujuan Pendidikan}

Ada empat tujuan pendidikan dalam pandangan Syekh Sulaiman al-Rasuli. Pertama, memperoleh kebahagiaan dunia dan akhirat. Orang yang bahagia dunia akhirat adalah: "Orang yang iman lagi shaleh lagi membayarkan segala hak Allah Ta'ala dan hak segala makhluk lagi mengikut dari syari'at pada zahir dan batin lagi berpaling dari pada perhiasan dunia yang lata ini." (SSA,1346H/1927M: 62). Kedua, menjadi hambaAllah. Menuntut ilmu lewat proses pendidikan pada hakikatnya dilakukan agar manusia itu mampu beribadah kepada-Nya secara benar. Setiap aktivitas yang tidak didasari oleh ilmu yang benar, maka ia tidak termasuk dalam kategori "amal dalam pandangan Syarak." (SSA, 1929: 128). Ketiga, memiliki akhlak mulia. Mendidik akhlak yang baik itu perlu pendidikan di lembaga formal. Seseorang yang tidak sekolah atau tidak berpendidikan cenderung terpengaruh dengan lingkungannya (SSA, 1930: 10-11). Keempat, menjadi insan yang cerdas. Dengan belajar ke sekolah, maka seorang anak akan mampu tulis-baca dan berhitung. Dengan begitu ia bisa berbuat sesuatu dengan senang hati sehingga memperoleh keselamatan dan kebahagiaan yang sesungguhnya (SSA, 1930: 12).

3) Materi

Syekh Sulaiman al-Rasuli memandang bahwa materi pendidikan yang paling utama adalah ilmu-ilmu yang berorientasi pada tafaqquh fi al-din. Ilmu-ilmu tersebut dituntut hendaklah atas motivasi keimanan kepada Allah sehingga muncul sifat ikhlas karena Allah semata, bukan untuk duniawi (SSA, 1930: 26). Ia tidak menolak ilmu-ilmu dalam kategori umum, tetapi ia mengkritik orang-orang yang sibuk menuntut ilmu dunia tetapi tidak mengetahui ilmu-ilmu agama. Menurutnya, perkembangan ilmu agama semakin lama semakin berkurang. Berbeda halnya dengan ilmu umum yang semakin lama semakin berkembang, 
Volume V No. 2, Agustus 2014

apalagi adanya pergaulan dengan budaya bangsa asing yang banyak hal bertentangan dengan ajaran agama. Tetapi, sulit melahirkan para mujtahid di bidang agama, karena cahaya nubuwah semakin lama semakin gelap (SSA, 1346 H/1927 M: 57). Karena itu, kajian ilmu agama menjadi prioritas.

Di antara materi pendidikan yang harus dipelajari, dapat diklasifikasikan menjadi enam, yaitu: 1) Al-Qur'ān dan Hadis; harus didukung oleh ilmu-ilmu lain, di antaranya: Ilmu bahasa Arab yang memiliki dua belas cabang, Ilmu ushul, Ilmu al-Qur' 'ān, Ilmu Hadis; dan Ilmu-ilmu alat dalam berijtihad; 2) Bahasa Arab sebagai ilmu alat; 3) Aqidah/Tauhid; 4) Fiqh; 5) Akhlak; dan 6) Keterampilan (SSA, 1930: 29-30).

\section{4) Metode Pendidikan}

Jika ditelaah karya-karya Syekh Sulaiman al-Rasuli, dapat dirumuskan bahwa terdapat lima metode penting dalam pendidikan. Pertama, metode keteladanan. Ia menyebutkan bahwa seorang guru harus menjadi "suluah bendang di nagari, camin taruih dalam suku...(SSA, 1930: 30), yang bermakna bahwa seorang guru harus seperti cermin. Peserta didik cenderung meniru perkataan dan perbuatan gurunya. Kedua, metode kisah. Pentingnya metode kisah tampak dalam kitabnya "Pedoman Hidoep di Alam Minangkabau," yang menjelaskan pola pendidikan Siti Budiman yang menggunakan metode kisah untuk mendidik anaknya (SSA, 1930: 20). Ketiga, metode nasehat. Keempat, metode bertahap (al-tadrijj). Kelima, metode pembiasaan. Pembiasaan sejak usia dini relevan dengan pepatah Minangkabau yang juga ia kutip: "maso ketek taranja-ranja, lah gadang tabao-bao, sampai tuo tarubah tido,” (SSA, 1930: 11).

Selain dari lima metode di atas, dapat pula dirumuskan enam prinsip metode pendidikan Islam dalam gagasan Syekh Sulaiman. Pertama, prinsip kesesuaian psikologi perkembangan jiwa anak. Ia menulis, "Hikmah dan gunanya merahasiakan sebahagian dari pada ilmu kepada setengah manusia ialah karena dada manusia itu belum patut menerima ilmu yang dirahasiakan itu, seperti kanak-kanak yang belum mempunyai gigi dan geraman, tidak boleh diberi makanan keras." (SSA, 1954: 10). Kedua, prinsip kesesuaian dengan tingkat kecerdasan peserta didik. Ketika 


\section{At-Tarbiyah}

menasehati anak yang masih kecil, ia berpesan: "Kalau ditunjukdiajari, pemahaman dan daya akalnya belum sempurna, rasanya tidak akan lekat apa yang disampaikan. Seperti air hujan jatuh ke pasir, bagaikan sumpit diisi nasi, masuk bisa tapi rasanya tak ada yang dapat.Kalau sudah masuk dia ke sekolah, sudah berpaham dan berakal agak sedikit, sudah paham apa yang dikatakan, di situlah baru ditunjuk diajari, Insya Allah bisa melekat." (SSA, 1930: 13). Ketiga, prinsip kesesuaian dengan lingkungan di mana ilmu tersebut akan disampaikan. Ia menulis, Sungguah pun anak basekolah, salamo nyawo di kanduang badan, agamo jangan anak gadaikan, adat jangan anak jual. (SSA, 1930: 22). Maka sesuaikan pelaksanaan pendidikan dengan kearifan lokal. Keempat, prinsip penyajian materi secara tertib, sesuai alur dan patut. Ia menulis, "Menuntut ilmu harus tertib, dahulukan yang fardhu baru yang sunat-sunat" (SSA, 1930: 26). Kelima, prinsip spesifikasi keilmuan. Ia menulis, "Mambali sabanyak pitih, bababan kiro katajujuang, mamakan kiro katalulua. Jangan bak cando urang kini, sifat rambang dipakainyo, itu taragak iko katuju, makasuid sagalo pandai," (SSA, 1930: 26). Nasehat ini mengandung makna bahwa ilmu yang dituntut itu harus spesifik, jangan semua bidang keilmuan yang di luar kemampuan ingin dikuasai. Keenam, prinsip holistik dan terintegrasi dalam penyajian materi. Ia (1930: 30) menulis "Kalau mengaji di sekolah, kajilah kitab hingga tuntas, dari awal lalu ke akhirnya, dari pangkal hingga ke ujung, maksud matan pahami betul, yang mutlak ada kaidahnya, yang umum ada khususnya, letakkan ayat di tempatnya, begitu pula hadis nabi, perkataan ulama dalam kitab, jangan ditukar maksudnya."

\section{d. Pendidik}

Syekh Sulaiman al-Rasuli memahami peran guru sebagai ulama yang tidak saja bertugas untuk mendidik peserta didiknya di surau atau sekolah, tetapi berperan sebagai orang yang memiliki ilmu secara mendalam, sebagai pelindung dan pembimbing bagi masyarakat. Dalam hal ini, istilah yang digunakannya adalah "jadi guru di nan banyak, suluah bendang di nagari, camin taruih dalam suku, tampek batanyo di rakyat." (1930: 30-31). Namun Syekh Sulaiman (1930: 60) mengkritik ulama dengan membanginya kepada tujuh bagian. Pertama, ulama matahari, yaitu tipe guru 
Volume V No. 2, Agustus 2014

yang ideal, profesional dalam menjalankan tugasnya, mendidik, mencerdaskan, dan mencerahkan peserta didiknya serta menjadi teladan dan penuh kasih sayang. Kedua, ulama sumbu lampu; yaitu tipe guru yang pandai menyampaikan materi, tetapi tidak menjadi teladan. Ketiga, ulama nan pamacah, yaitu guru yang bersifat provokatif, pembela status quo, sulit menerima apalagi melakukan inovasi/perubahan yang positif. Keempat, ulama banyak lancah (pejalan), yaitu tipe guru yang selalu meninggalkan tugas pokoknya di sekolah, suka keluar tanpa alasan yang benar. Anehnya, jika ia benar berkunjung ke tempat lain, kunjungannya tidak meninggalkan pesan positif bagi orang lain. Kelima, ulama bak kancah yaitu tipe guru yang berpangku tangan, tidak mau tahu tentang program sekolah. Jika ada inovasi pendidikan yang diterapkan, ia tidak memberi respons; menolak atau menerima. Keenam, ulama ruok sabun (busa sabun), yaitu tipe guru yang kurang ilmu, hanya pandai berapologi dan banyak bicara. Kompetensinya rendah, tetapi pandai berkilah. Ketujuh, ulama nan pangkauik, yaitu tipe guru yang pragmatis dan materialistis.

Selain itu, terdapat pula gagasan Syekh Sulaiman (1930: 30-32) yang dapat dikategorikan sebagai kode etik pendidik, yaitu: 1) menjadi teladan bagi orang lain, 2) memiliki jiwa sosial yang tinggi atau pandai bermasyarakat, 3) bekerja sama dengan umara, 4) bersifat Adil (tagak luruih) kepada peserta didik, 5) penuh kasih sayang kepada peserta didik, 6) memperlakukan peserta didik seperti anak kandung, 7) memiliki sifat ikhlas, 8) hati-hati dalam berpendapat dan jangan tergesa-gesa, 9) mengakui kelemahan diri jika tidak mengetahui, dan 10) menghormati orang yang lebih mendalam ilmunya.

\section{e. Peserta Didik}

Syekh Sulaiman al-Rasuli (1930: 26-30) mengemukakan beberapa sifat dan kode etik yang harus dimiliki oleh peserta didik, 1) berniat menuntut ilmu karena Allah, ia menulis, "baikkan niat jo sangajo, menuntut karano Allah;" 2) mengamalkan ilmu yang telah diperoleh dengan orientasi akhirat, ia menulis, "Apa saja ilmu dan kaji yang sudah didapat dan sudah terasa matang, harus dipakai diamalkan untuk bekal pulang ke negeri akhirat;" 3) berperilaku sesuai dengan adat dan ajaran agama, ia berpesan, "Sungguah pun anakbasekolah, salamo nyawo di kanduang badan, 


\section{At-Tarbiyah}

agamo jangan anak gadaikan, adat jangan anak jual, kepandaian buliah kito cari, asal manfaat pado kito;" 4) berpendirian tetap, ia menulis, "Kepandaian boleh kita cari, asal manfaat pada kita, tapi pendirian tetap-tetap, jangan berpaham seperti ujung batuang (bambu), kemana angin yang keras ke sana rebah ujungnya;" 5) bersifat pemalu dan jangan berperilaku sumbang (ganjil); 6) rajin dan bekerja keras; dan 7) bersifat tawadhu' dan menghormati orang yang lebih alim.

Di samping itu, ada tiga adab seorang murid kepada gurunya, yaitu: 1) mematuhi perintah guru selagi tidak bertentangan dengan Syarak; 2) bersalaman dengan guru jika bertemu, dan 3) berterima kasih kepada guru dan jangan melawan kepadanya. Ia menulis, "Jasa guru bukan satu, lebih dari ayah kandung, dari neraka ia hindarkan, dari bodoh ia cerdaskan, wajib sekali berterima kasih kepadanya, sebagai tanda syukur membalas jasa. "'(SSA, 1930: 23 dan 28).

Bapak kandung yang dimaksud di sini tampaknya lebih kepada orang tua biologis yang lebih bertanggungjawab membesarkan anaknya secara fisik, maka lebih berjasalah guru yang bertindak sebagai orang tua rohani (abu al-ruh). Ia (1930: 29) juga menyebut murid yang melawan kepada guru, tidak saja kehilangan berkah dari ilmunya, tetapi juga bisa mendatangkan mala petaka atau azab baginya di dunia ini.

\section{1) Pendidikan Informal}

Syekh Sulaiman (1930: 54-55) mencela seorang ayah sebagai kepala keluarga yang tidak bertanggung jawab terhadap istri dan pendidikan anak-anaknya. Orang tua seperti itu tidak berbeda dengan hewan yang kawin dan berketurunan tanpa mendidiknya, kelak ia mendapat azab di neraka. Ia juga menggambarkannya dalam pepatah Minangkabau "Aia janiah sajak di hulu ka muaro janiah juo, asal jangan kotor di jalan". Maknanya, jika orang tua itu memberikan pendidikan yang baik kepada anak-anaknya, maka kelak anak itu akan menjadi anak yang shaleh hingga akhir hayatnya. Sedangkan kalimat "asalkan jangan kotor di jalan" bermakna pendidikan dari orang tua tidak satu-satunya faktor yang mempengaruhi kepribadian seseorang, tetapi juga ada pengaruh lingkungan yang harus diwaspadai. 
Volume V No. 2, Agustus 2014

Pendidikan dalam keluarga (informal) dilakukan sejak masa sebelum menikah atau dalam modern disebut pendidikan prenatal (tarbiyah qabl al-wiladah). Masa ini dimulai dari pemilihan jodoh. Menurutnya, meskipun keluarga telah sepakat untuk menikahi seorang perempuan, tetapi laki-laki yang akan menikah tersebut harus mengenal karakter perempuan itu. Pilihlah perempuan yang taat beragama, berakhlak mulia dan bisa dididik (1930: 58). Pada fase pernikahan, hendaklah seorang suami dan istri mengetahui akhlaknya masing-masing.

Setelah itu, Syekh Sulaiman(1930: 54-55) juga mengemukakan pendidikan setelah melahirkan atau pascanatal (tarbiyah ba'd al-wiladah). Dalam hal ini, ia menegaskan beberapa kewajiban orang tua dalam mendidik anaknya setelah lahir, seperti: pada usia tujuh hari, sembelih hewan akikah, cukur rambut dan beri namanya; pada usia tujuh tahun, suruh shalat dan membaca al-Qur'ān lalu sekolahkan. Utamakan sekolah agama agar ia kenal ajaran agama.

4. Penerapan Gagasan Syekh Sulaiman pada MTI

Sebagian besar gagasan pendidikan Islam Syekh Sulaiman al-Rasuli di atas masih diterapkan di Sumatera Barat, dalam hal ini di MTI Canduang, MTI Jaho, dan MTI Batang Kabung, baik pada komponen tujuan, materi, metode, pendidik dan peserta didik dengan bentuk yang berbeda. Seperti penerapan gagasan tentang hakikat manusia, sebagai makhluk jasmani, dilakukan pembinaan olahraga. Pendidikan rohani dilaksanakan dengan pembiasaan zikir sesudah shalat, membaca al-Qur'ān, shalawat, dan tausiyah. Khusus di MTI Batang Kabung, pendidikan rohani juga dilakukan melalui tarekat Syathāriyah untuk kelas VII. Pembinaan fungsi manusia sebagai hamba (' $a b d$ ) Allah, di ketiga MTI ini melakukan pembiasaan shalat fardhu berjamaah. Namun, ibadah sunnah, seperti shalat tahajud, dan puasa sunnah belum ditekankan, hanya kemauan dari santri sendiri. Pembinaan khalifah Allah di muka bumi dilakukan melalui pembinaan kepemimpinan, yaitu membentuk pengurus OSIS. Pembinaan manusia sebagai makhluk individu dan social, dilakukan dengan membina sikap kemandirian. Di MTI Jaho, pembinaan sosial itu dilakukan dengan berpartisipasi aktif dalam kegiatan masyarakat, terutama yang terkait dengan kegiatan keagamaan. Di MTI Batang Kabung, 


\section{At-Tarbiyah}

dibangun pula tradisi mando'a bagi santri yang berkelahi. Kedua santri yang berkelahi diharuskan menyembelih seekor ayam lalu memakannya secara bersama santri lain yang dibimbing oleh buya ketika mando'a tersebut. Biaya penyembelihan ayam itu ditanggung oleh santri yang berkelahi.

Namun ada hal-hal yang tidak sepenunya diterapkan sebagaimana yang menjadi gagasan Syekh Sulaiman al-Rasuli. Di antara yang paling menonjol adalah model kurikulum yang diterapkan, khususnya terkait dengan materi pembelajaran, tidak lagi fokus kepada ilmu-ilmu yang berorientasi pada tafaqquh $f i$ al-dìn semata, tetapi ketiga MTI yang diteliti telah menerapkan kurikulum pesantren khalafiyah yang mengkombinasikan antara kurikulum pondok pesantren dengan kurikulum nasional (seperti SMP dan SMA) dan kurikulum madarasah Kementerian Agama. Meskipun di satu sisi pola ini menguntungkan dengan wawasan keilmuan yang lebih komprehensif serta dianggap terbuka dan respons terhadap perkembangan zaman, akan tetapi alokasi waktu yang terlalu besar dan jumlah mata pelajaran (materi) yang banyak mengakibatkan pola pembelajaran kitab kuning sebagai salah satu tradisi MTI kurang optimal. Pola kurikulum seperti ini tentu tidak sesuai dengan prinsip metode pembelajaran yang tertib, sesuai dengan alur dan patut seperti yang dikemukakan Syekh Sulaiman al-Rasuli sendiri.

Begitu pula pendidik, perannya sebagai ulama seperti yang dikemukakan Inyiak Canduang tentu tidak sepenuhnya dapat dilakukan oleh semua guru. Peran ini lebih memungkinkan untuk diterapkan oleh guru-guru kitab kuning, selain memiliki ilmu agama juga berperan aktif di tengah-tengah masyarakat. Peran pendidik sebagai ulama ini lebih tampak di MTI Batang Kabung di mana para guru yang bergelar Tuanku umumnya memiliki jamaah secara khusus di masjid/mushalla dan mereka yang tinggal di sekitar Batang Kabung tetap mendapat bimbingan dari pimpinan/khalifah MTI. Sementara MTI Canduang dan Jaho, guru-guru yang menjalankan perannya sebagai ulama di tengahtengah masyarakat tidak terorganisir, melainkan diserahkan pada pribadi masing-masing. Bahkan MTI Canduang saat ini "kehilangan" sosok ulama yang berperan sebagai "Buya" atau semacam "Kiai" yang tinggal di sekitar MTI, menjadi figur dan model bagi santri dalam kehidupan sehari-hari dan aktif mengajar 
dan mendidik santri baik dalam kegiatan intrakurikuler maupun di luar pembelajaran.

Selanjutnya peserta didik atau santri di ketiga MTI ini memiliki akhlak yang bervariasi. Akhlak peserta didik tersebut sesungguhnya dipengaruhi oleh banyak faktor, terutama latar belakang keluarga dan lingkungan sekitarnya. Namun, MTI sebagai lembaga pendidikan Islam akan lebih mudah membina akhlak santrinya apabila: 1) santri diasramakan lalu dilakukan pembinaan yang kontiniu dan terorganisir; 2) santri dikontrol dari pengaruh negatif kemajuan teknologi informasi; dan 3) dukungan lingkungan sekitar terhadap pergaulan santri agar tetap sesuai dengan tuntunan agama dan adat. Ketiga hal ini tampak di MTI Jaho di mana seluruh santri diasramakan, mereka tidak dibebaskan menggunakan internet, TV, bahkan HP dan kultur masyarakat sekitar pun masih mendukung keberadaan santri dengan menggap mereka sebagai anak nagari. Karena itu, santri MTI Jaho, secara umum tampak lebih santun dan pemalu, meskipun pembinaan di asrama masih belum optimal. Sedangkan di MTI Canduang dan MTI Batang Kabung, lebih banyak yang tidak tinggal di asrama dan mereka tidak bisa dikontrol ketika bersentuhan dengan teknologi informasi seperti internet, sehingga dampak negatif dari kemajuan tersebut bisa mempengaruhi akhlak mereka. Apalagi santri di MTI Batang Kabung yang tidak tinggal di asrama dan berada di perkotaan di mana kultur masyarakatnya tidak lagi kokoh seperti di kanagarian yang ada di Canduang dan Jaho. Maka perilaku santri yang tidak tinggal di asrama ini tampak beberapa di antaranya kurang santun dalam berperilaku, termasuk dalam pergaulan antara laki-laki dan perempuan. Sementara santri yang diasrama lebih terkontrol dalam beribadah sehari-hari dan belajar di malam hari sehingga kesungguhan mereka dalam belajar dan adab mereka pada guru masih bisa dirasakan, walau pun di sisi lain sebagian mereka turut terpengaruh dengan teman-teman sebayanya yang tidak tinggal di asrama tersebut.

\section{F. PENUTUP}

1. Kesimpulan

Berdasarkan gagasan Syekh Sulaiman al-Rasuli tentang pendidikan 


\section{At-Tarbiyah}

Islam di atas dapat disimpulkan bahwa ia patut disebut sebagai tokoh pendidikan Islam. Paling tidak ketokohannya di bidang pendidikan Islam dapat dilihat dari tiga aspek. Pertama, ia adalah praktisi pendidikan Islam di mana ia aktif sebagai pendidik dan pengajar, khususnya di MTI Canduang. Kedua, Ia adalah tokoh pembaharu pendidikan Islam di masanya, mulai dari penggunaan kitab yang bervariasi ketika mengajar di Surau Baru pasca-kembali dari Mekah hingga mengubah sistem halaqah di surau menjadi sistem klasikal pada madrasah yang kemudian dikenal dengan Madrasah Tarbiyah Islamiyah (MTI) Canduang lalu perubahan itu diikuti oleh surausurau lain dari kalangan ulama kaum Tuo. Ketiga, ia termasuk tokoh yang memiliki gagasan tentang pendidikan Islam, yang ia tulis dari beberapa kitabnya. Bahkan kemampuan Syekh Sulaiman al-Rasuli tidak hanya di bidang fiqh saja - seperti yang dipahami banyak orang - tetapi karya-karya tulisnya menyentuh tiga pokok ajaran dasar Islam itu sendiri, yaitu di bidang aqidah (seperti al-Aqwālu al-Mardhīyah, Jawāhir al-Kalāmiyah, Tablīgh al-Amānāt), syari'ah (seperti Kitab Pedoman Puasa), dan akhlak (seperti Dawa'ul Qulub, Enam Risalahdan sebagainya). Ia juga menulis tentang adat dan budaya Minangkabau yang ia kombinasikan dengan syari'at Islam (seperti Asal Pangkat Penghulu dan Pendiriannya dan Pertalian Adat dan Syarak yang Terpakai di Alam Minangkabau Lareh nan Duo Luhak nan Tigo). Penguasaannya terhadap ajaran/syariat Islam dengan adat dan budaya Minangkabau tersebut tampak berpengaruh pada gagasannya tentang pendidikan Islam, terutama dalam kitabnya: Pedoman Hidoep di Alam Minangkabau (Nasehat Siti Boediman) Menoeroet Garisan Adat dan Sjara'.

Dengan begitu, gagasan pendidikan Islam Syekh Sulaiman al-Rasuli memiliki corak tafaqquh di al-dīn bernuansa kultural. Ia mengedapankan kajian terhadap ilmu-ilmu agama, tetapi tidak tercerabut dari kearifan lokal. Corak pemikiran ini tentu relevan dengan filosofi Minangkabau yang selalu ia kemukakan, yaitu "Adat Basandi Syarak, Syarak Basandi Kitabullah, Syarak Mangato, Adat Mamakai."

Namun tidak semua komponen pendidikan Islam yang ia bahas pada karya-karya tulisnya. Gagasannya tentang pendidikan Islam yang dapat diterapkan pada madrasah dalam konteks kekinian hanya meliputi: hakikat manusia, tujuan pendidikan, materi, metode, kode etik pendidik, sifat dan kode etik peserta didik serta pendidikan 248 | Gagasan Syekh Sulaiman Al-Rasuli... 
informal.

Penerapan gagasan Syekh Sulaiman al-Rasuli pada MTI di Sumatera Barat, dalam hal ini MTI Canduang, MTI Jaho, dan MTI Batang Kabung, sebagian besar masih diterapkan di ketiga MTI ini. Namun ada hal-hal yang tidak sepenunya diterapkan, seperti yang dijelaskan sebelumnya. Adanya ketidaksesuaian dengan gagasannya dengan apa yang diterapkan di MTI saat ini, turut dipengaruhi oleh ketidakpahaman pengelola, pendidik, hingga santri MTI terhadap gagasan Syekh Sulaiman al-Rasuli. Sebab, mereka tidak memiliki karya-karya tulis Syekh Sulaiman al-Rasuli, apalagi memahami pesan-pesan yang dikandungnya. Kecuali itu, hanya kitab al-Aqwāl al-Mardhiyah yang masih diterapkan oleh MTI Canduang dan Jaho, itu pun berbicara tentang tauhid tingkat dasar dengan I'tiqad Ahl al-Sunnah wa al-Jamā'ah. Jadi, jika ada yang masih relevan dengan gagasan Syekh Sulaiman al-Rasuli di ketiga MTI ini lebih disebabkan oleh faktor tradisi yang terpelihara sejak awal berdirinya, bukan sebagai akibat langsung dari gagasannya yang tertulis dalam karya-karyanya.

\section{Rekomendasi}

Bagi pimpinan, guru atau pengelola MTI perlu melakukan: (1) sosialisasi gagasan pendidikan Islam Syekh Sulaiman al-Rasuli terhadap unsur pimpinan, pendidik, tenaga kependidikan dan santri MTI sehingga gagasannya tetap menjadi referensi sekaligus inspirasi untuk mengembangkan dan meningkatkan kualitas MTI; (2) Melakukan reformulasi kurikulum MTI dalam menghadapi perkembangan modernisasi. Di satu sisi MTI perlu menerapkan kurikulum mata pelajaran umum sehingga MTI tetap survive dengan kemajuan sains dan teknologi. Namun di sisi lain, MTI harus tetap mempertahankan identitas aslinya sebagai lembaga pendidikan Islam yang melahirkan ulama, atau paling tidak generasi yang cerdas berpaham Ahl al-Sunnah wa al-Jamā'ah dan bermazhab Syafi'i; (3) MTI harus mengoptimalkan pembinaan santri di asrama. Bahkan MTI seharusnya lebih banyak menampung santri yang berasrama dari pada tidak sehingga lebih mudah melakukan pembinaan, baik aspek intelektual maupun moral-spiritualnya; (4) MTI harus melakukan kaderisasi terhadap ulama yang siap menjadi pendidik dan pemimpin madrasah sekaligus pendidik umat yang profesional dengan ilmu yang mendalam; dam (5) MTI harus mempertagas ciri khas atau spesifikasi 


\section{At-Tarbiyah}

keilmuan yang dimilikinya sehingga MTI menjadi lebih eksis dan berperan dalam menyiapkan lulusan yang berilmu pengetahuan.

Peran Persatuan Tarbiyah Islamiyah atau PERTI harus ditingkatkan untuk meningkatkan kualitas MTI. Sebab kelahiran organisasi ini berawal dari keinginan untuk mengorganisir MTI itu sendiri agar semakin berkembang dan meningkat kualitasnya. Apalagi organisasi ini hingga sekarang masih terpecah dua, yang satu lebih dikenal dengan singkatan "Tarbiyah", yang lainnya dengan singkatan PERTI. Seharusnya, keduanya melakukan ishlah dan kembali kepada khittahnya sebagai organisasi yang lebih mengedepankan urusan pendidikan lalu diperkuat dengan dakwah dan sosial.

\section{DAFTAR BACAAN}

Asnan, Gusti, Kamus Sejarah Minangkabau, (Padang: Pusat Pengkajian Islam dan Minangkabau (PPIM), 2003), hlm. 308.

Azra, Azyumardi, Surau; Pendidikan Islam Tradisional dalam Transisi dan Modernisasi, Jakarta: Logos Wacana Ilmu, 2003

Chairusdi, Sejarah Perjuangan dan Kiprah PERTI dalam Dunia Pendidikan Islam di Minangkabau, (Padang: IAIN Press, 1999

Dhofier, Zamakhsyari, Tradisi Pesantren: Studi tentang Pandangan Hidup Kyai, Jakarta: LP3ES, 1994, cet. ke-6

Edwar (ed.), Riwayat Hidup dan Perjuangan 20 Ulama Besar Sumatera Barat, Padang: Islamic Center Sumatera Barat, 1981.

Furchan, Arief dan Agus Maimun, Studi Tokoh; Metode Penelitian Mengenai Tokoh, Yogyakarta: Pustaka Pelajar, 2005

Al-Ghazali, Imam, Ihyā'Ulūm al-Dìn, Juz I (Beirut: Dar al-Fikr, 1991), cet. ke-3

Ilyas, Yusran, Syekh H. Sulaiman ar-Rasuli; Profil Ulama Pejuang 1871 - 1970, Padang: t.p., 1955

Kapau, Muhammad Rusli, Khulāsah Tārīkh al-Maulānā al-Syekh Sulaimān Al-Rasūli, ditulis dalam rangka peringatan 30 tahun mengajar Syekh Sulaiman ar-Rasuli, tepatnya pada tanggal 1 Septem-

250 | Gagasan Syekh Sulaiman Al-Rasuli... 
ber 1938 .

Koto, Alaiddin, Persatuan Tarbiyah Islamiyah: Sejarah, Paham Keagamaan, dan Pemikiran Politik 1945-1970, Jakarta: RajaGrafindo Persada, 2012

Latief, M. Sanusi, Gerakan Kaum Tua di Minangkabau, Disertasi: IAIN Syarif Hidayatullah Jakarta, 1988

Machudum, Sjarkawi, Perjuangan Persatuan Tarbiyah Islamiyah,Ahlussunnah wal Jama'ah Pendiri Republik Indonesia, Jakarta: Perpustakaan Persatuan Tarbiyah Islamiyah, 2011

Majalah Soearti No. 8 Tahun I, Dzulkaidah 1356 H/Januari 1938 M

al-Rasuli, Syekh Sulaiman, al-Aqwālu al-Mardhīyah, Fort de Kock: Mathba'ah al-Islamiyah, $1933 \mathrm{M} / 1351 \mathrm{H}$.

, al-Jawāhir al-Kalāmiyah fi Bayān 'Aqā'id al-Īmāniyah, Fort de Kock: Drukkerij Islamijah FDK, 1346 H/1927 M.

, Asal Pangkat Penghulu dan Pendiriannya, Fort de Kock: Mathba'ah Islamiyah, 1927.

, Dawā'al-Qulūb, Fort de Kock, Maktabah Islamiyah, 1924 , Enam Risalah; Isra' Mi'raj, Nabi SAW, Kisah Mu'adz r.a. dan wafatnya Nabi SAW, serta al-Qaul al-Kāsyffí al-Rad 'Ala min I'tiradh 'Ala Akābir al-Mu'allaf,Ibthal Hazhzhi Ahl al- 'Ashībah fì Tahrīm Qirā'at al-Qur'ān bi al-'Ajmiyah dan Izalat al-Dhalāl fì Tahrìm al-İdza'wa al-Sü' āl, Bukittinggi, Derekrij Agam, 1920.

, Keadaan Minangkabau Dahulu dan Sekarang, Majalah al-Mizan, Maninjau: Tahun Kesebelas, 26 Maret 1938/15 Muharram $1357 \mathrm{H}$ , Kitab Pedoman Puasa, Fort de Kock: Bukhandel, Tsamaratul Ikhwan, t.th., tulisan diselesaikan tahun 1936.Karya ini ditulis pada 27 agustus 1936 M/11 Rajab 1355 H. Kemudian dicetak oleh Bukhandel, Tsamaratul Ikhwan, Fort de Kock. , Maklumat "Sari Pati Sumpah Satie Bukit Marapalam" pada tanggal 7 - Juni 1964 M/26 Muharam 1384 Hdi Candung. , Mari Bersatu Dengan Adat dan Syarak, Padang: Syiar Tarbiyah, Ikatan Pemuda Tarbiyah Islamiyah (IPTI) edisi Pebruari 2013. Tulisan ini diterbitkan di Harian Haluan yang dimuat pada tanggal 16-19 April 1951 secara bersambung , Nasihat Maulana Sjeich Soeleiman Ar Rasoeli, Majalah 


\section{At-Tarbiyah}

Soearti edisi 22 tahun ke III Maret 1939 M/Muharram 1358 H , Pedoman Hidoep di Alam Minangkabau Nasihat Siti Boediman Menoeroet Garisan Adat dan Syara', Dicetak atas Nafkah Dt. Mangoelak Basa, Bukittinggi: Tsamaratoel Ichwan, 1930/1358 , Pertalian Adat dan Syarak yang Terpakai di Alam Minangkabau Lareh nan Duo Luhak nan Tigo, Fort de Kock: Mathba'ah Islamiyah, 1927.

, Risālah al-Qaul al-Bayān fi Tafsīr al-Qur'ān, Fort de Kock: Mathba'at Islamiyah, 1929,

, Tabligh al-Amanah, Bukittinggi, 1954 M/1373 H

, Tsamarat al-Ihsān fïWalādatSayyid al-Insān, Bukittinggi:

Direkrij, 1923.

Rusli, Bahruddin, Ayah Kita, (Cetakan pertama yang dicetak stensilan dalam rangka HUT MTI Canduang ke-50 bulan Mei 1978

Rusli, Bahruddin, Mengenang Dua Ulama Besar: Inyiak Parabek dan Inyiak Canduang, (Jakarta, ditulis tanggal 26 Juli 1972

Satori, Djama'an dan Aaan Komariah, Metodologi Penelitian Kualitatif, Bandung: Alfabeta, 2010, cet. ke,2

Shamad, Irhash A. dan Danil M. Chaniago, Islam dan Praksis Kultural Masyarakat Minangkabau, (Jakarta: Tintamas Indonesia, 2007

Steenbrink, Karel A., Pesantren, Madrasah, Sekolah: Pendidikan Islam dalam Kurun Moderen, Jakarta: LP3ES, 1994, cet. ke-2

Suprayogo, Irman dan Tobroni, Metodologi Penelitian Sosial-Agama, (Bandung: PT. Remaja Rosdakarya, 2001

Yunus, Yulizal, Syekh Sulaiman al-Rasuli (1971-1970) dalam "Beberapa Ulama di Sumatera Barat", (Padang, Pemerintah Provinsi Sumatera Barat, Dinas Pariwisata Seni dan Budaya UPTD Museum Adityawarman, 2008)

Zulkifli, Syekh Sulaiman al-Rasuli; Upaya Pembaharuan Pendidikan Islam di Minangkabau, Tesis: PPs IAIN IB Padang. 2010 